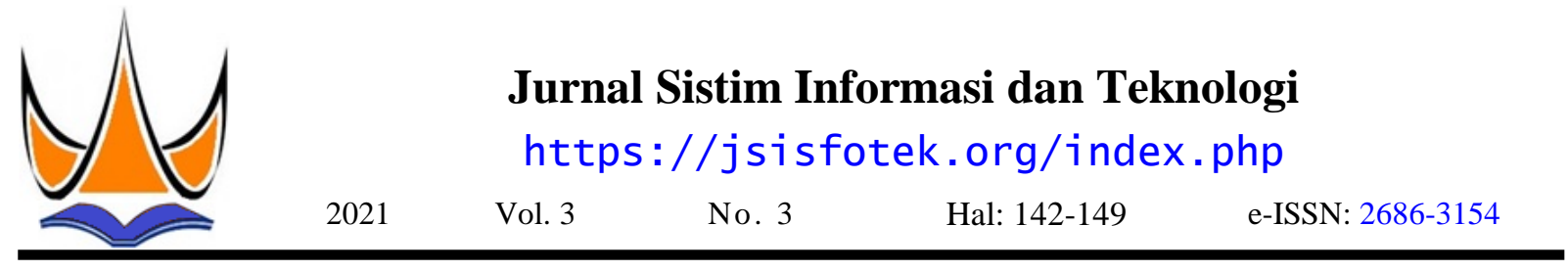

\title{
Optimalisasi Penentuan Kriteria Penerima Bantuan Program Indonesia Pintar dengan Metode TOPSIS
}

\author{
Dina Ayudia $^{1 凶}$, Gunadi Widi Nurcahyo $^{2}$, Sumijan $^{3}$ \\ ${ }^{1,2,3}$ Universitas Putra Indonesia YPTK Padang \\ dinaayudia6216@gmai1.com
}

\begin{abstract}
The distribution of scholarships is carried out to assist in the determination of recommending someone who deserves to receive a scholarship, a Decision Support System is needed because the system for selecting scholarship candidates is still manual, and has many weaknesses. The large number of scholarship participant applicants makes schools having difficulty handling manual data processing so that software is needed to simplify the data processing. There for not all students who apply to receive scholarships can be granted, because the number of students who apply is very large, it is very necessary to build an SPK with the Technique for Order Preference by Similarity to Ideal Solution (TOPSIS) method which can help provide recommendation for scholarship recipients. Based on the analysis of the DSS with the TOPSIS method, it was carried out by means of a questionnaire, interview observation and system implementation. In the assessment of scholarship acceptance, it can be used as a basis for facilitating decisions on scholarship recipients because the system will process data and provide information quickly, precisely and consistently to the principal of students to receive the best scholarships to be awarded. Can form a decision that is right, effective and efficient in managing data on student recipients who are truly entitled to receive the scholarship. The TOPSIS method can be used to determine scholarship recipients, SPK in the assessment of scholarship acceptance can facilitate decisions in grade 7 students of SMP Negeri 17 Padang proportionally based on the results of student data processing including family cards, parents 'jobs, parents' income, number of dependents of parents and age parents accurately and accurately because the system can minimize errors in the process of calculating data normalization.
\end{abstract}

Keywords: Decision Support System (DSS), Technique for Order Preference by Similarity to Ideal Solution (TOPSIS), Scholarship, Optimization, Smart.

\begin{abstract}
Abstrak
Pembagian beasiswa dilakukan untuk membantu penentuan dalam merekomendasikan seseorang yang layak menerima beasiswa maka dibutuhkan Sistem Pendukung Keputusan, dikarenakan sistem pemilihan calon penerima beasiswa masih manual, dan banyak sekali kelemahannya.Banyaknya pendaftar peserta beasiswa membuat sekolah mengalami kesulitan dalam menangani pengolahan data yang manual sehingga diperlukan perangkat lunak untuk mempermudah pengolahan data tersebut. Oleh karena itu tidak semua siswa yang mengajukan permohonan untuk menerima beasiswa dapat dikabulkan, karena jumlah siswa yang mengajukan permohonan sangat banyak, maka sangat dibutukan sekali untuk dibangun suatu SPK dengan metode Technique for Order Preference by Similarity to Ideal Solution (TOPSIS) yang dapat membantu memberikan rekomendasi bagi penerima beasiswa. Berdasarkan analisis terhadap SPK dengan metode TOPSIS ini dilakukan dengan cara kuesioner, observasi wawancara dan implementasi sistem. Dalam penilaian penerimaan beasiswa dapat dijadikan dasar untuk mempermudah keputusan pada penerima beasiswa karena sistem akan mengolah data dan memberikan informasi dengan cepat, tepat dan konsisten kepada kepala sekolah terhadap siswa untuk menerima beasiswa terbaik yang akan diberikan. Dapat membentuk suatu keputusan yang tepat, efektif dan efisien dalam pengelolaan data penerima besiswa yang benarbenar berhak menerima beasiswa. Metode TOPSIS dapat digunakan untuk menentukan penerima beasiswa, SPK dalam penilaian penerimaan beasiswa dapat mempermudah keputusan pada siswa kelas 7 SMP Negeri 17 Padang secara proporsional dengan berdasarkan hasil proses data siswa meliputi kartu keluarga, pekerjaan orang tua, penghasilan orang tua, jumlah tanggungan orang tua dan usia orang tua dengan tepat dan akurat karena sistem dapat meminimalisir kesalahan dalam proses perhitungan normalisasi data.
\end{abstract}

Kata kunci: Sistem Pendukung Keputusan (SPK), Technique for Order Preference by Similarity to Ideal Solution (TOPSIS), Beasiswa, Optimalisasi, Pintar.

\section{Pendahuluan}

Selama proses pendidikan beasiswa merupakan bentuk penghargaan terhadap siswanya. Faktor utama yang sering menjadi kendala dalam menempuh pendidikan di Indonesia adalah tingginya biaya pendidikan. Untuk mengatasi tingginya biaya pendidikan pemerintah telah membuat program yang diberi nama Program Indonesia (c) 2021 JSisfotek

Pintar, di mana program tersebut memberikan bantuan tunai pendidikan kepada anak usia sekolah enam sampai dua puluh satu tahun yang berasal dari keluarga miskin, agar mendapatkan layanan pendidikan sampai tamat sekolah menengah atas baik melalui jalur pendidikan yang formal maupun pendidikan yang non formal. 
Beasiswa merupakan suatu bantuan keuangan bagi Penelitian yang sudah dilakukan oleh Riki Rinaldo pelajar dapat berupa dana sebagai penunjang biaya (2019) mengenai SPK menggunakan metode TOPSIS yang harus dikeluarkan untuk keberlangsungan dalam pemilihan beasiswa SI STMIK Pringsewu [8], pendidikan yang ditempuh [1]. Beasiswa bisa dikatakan penelitian selanjutnya dilakukan oleh Liesnaningsih sebagai pembiayaan yang bukan bersumber dari (2020) tentang menentukan santri penerima beasiswa pendanaan sendiri, akan tetapi diberikan oleh [9]. Selanjutnya penelitian oleh Aisyah (2020) tentang pemerintah, perusahaan swasta, universitas, serta SPK pemberian reward karyawan RS PKU lembaga pendidik atau peneliti yang memberikan Muhammadiyah Gambing [10], sama halnya penelitian kesempatan untuk meningkatkan kapasitas sumber daya oleh Ani (2017) tentang SPK penentuan penerima manusianya melalui pendidikan. Pendanaan tersebut beasiswa SMK MADYATAM.

diberikan kepada yang berhak menerima, sesuai dengan

kualifikasi, kualitas, dan kompetensi si penerima beasiswa [2].

Penelitian oleh Ramadiani (2020) metode TOPSIS untuk penentuan penerimaan beasiswa bidikmisi untuk mahasiswa, Gede Teguh melakukan penelitian tentang Sistem Pendukung Keputusan (SPK) adalah suatu SPK calon penerima bidikmisi. Sukiman 2020 metode sistem informasi yang dituju yang bersifat TOPSIS dapat menentukan beasiswa dengan cepat dan semiterstruktur dalam pengambilan keputusan [3]. meminimalisisr kesalahan pada proses.

Lebih lanjut menyatakan SPK bahwa pada dasarnya dikenal juga sebagai Decision Support System (DDS)

yang merupakan pengembangan lebih lanjut dari Secara umum Sistem Pendukung Keputusan (SPK) sistem informasi menajemen terkomputerisasi yang didefinisikan sebagai sebuah sistem yang mampu dibuat sedemikian rupa sehingga bersifat interaktif memberikan kemampuan dalam pemecahan masalah dengan pemakaiannya [4].

Technique for Order Preference by Similarity to Ideal Solution (TOPSIS) dikemukana pertama kali oleh Yoon dan Hwang pada tahun 1981 untuk digunakan sebagai salah satu metode dalam memecahkan masalah multikriteria [5]. Metode TOPSIS pertama kali disampaikan oleh Yoon dan Hwang, merupakan metode beberapa kriteria sederhana dan efisien untuk Metode TOPSIS (Technique for Order Perfomance by mengidentifikasi solusi dari himpunan beberapa Similarity to Ideal Solution) adalah suatu metode alternatif [6]. TOPSIS adalah prosedur yang berguna pengambilan keputusan multikriteria. TOPSIS dan berharga untuk penentuan posisi dan penentuan menggunakan prinsip bahwa alternatif yang dipilih berbagai keputusan jarak jauh pilihan melalui langkah- harus mempunyai jarak terdekat dari solusi ideal positif langkah pemisahan. TOPSIS memberikan lingkungan dan jarak terpanjang (terjauh) dari solusi ideal negatif yang efektif untuk membandingkan setiap alternatif dari sudut pandang geometris dengan menggunakan berdasarkan kriteria yang ada, nilai numerik tidak jarak Euclidean (jarak antara dua titik) untuk cocok untuk menafsirkan representasi dari penilaian menentukan kedekatan relatif dari suatu alternatif manusia berdasarkan masalah nyata [7].

Program Indonesia Pintar ini diharapkan dapat membantu siswa memenuhi kebutuhan dalam kegiatan a. TOPSIS dimulai dengan membangun sebuah pembelajaran dan diharapkan dapat membantu matrikskeputusan $\mathrm{Z}$ yang mengacu kepada $\mathrm{m}$ alternatif meringankan biaya personal peserta didik, baik biaya yang akan dievaluasi berdasarkan kriteria, matriks m secara langsung maupun tidak langsung kepada siswa dapat dilihat pada Persamaan (1).

yang kurang mampu agar bisa bersekolah dan mendapatkkan akses pendidikan yang layak.

Pada SMP Negeri 17 Padang setiap tahun ajaran baru selalu melakukan penseleksian terhadap siswa kelas 7 dengan kuota yang menerima beasiswa yang telah ditentukan oleh pihak sekolah. Banyaknya pendaftar beasiswa membuat SMP Negeri 17 Padang memiliki tantangan dalam menentukan keputusan, karena pengelolaan data yang masih manual dalam memberikan beasiswa kepada siswa yang benar-benar berhak mendapatkan beasiswa. Masalah yang selalu terjadi saat penseleksian adalah banyaknya waktu yang terbuang dalam perekapan data dari siswa karena harus di filter satu demi satu berdasarkan data yang telah diberikan siswa dan selalu sulit dalam memutuskan hasil yang sesuai sehingga kurang tepat sasaran dalam menentukan pemberian beasiswa.
$\mathrm{Z}=\left\{\begin{array}{c}B_{1} Z_{11} Z_{12} Z_{13} \ldots Z_{1 n} \\ B_{2} Z_{11} Z_{22} Z_{23} \ldots . Z_{2 n} \\ B_{3} Z_{31} Z_{32} Z_{33} \ldots Z_{3 n} \\ B Z_{m 1} Z_{m 2} Z_{m 3} \ldots . Z_{m n}\end{array}\right\}$

Di mana $B_{o}(i=1,2,3, \ldots . m)$ yaitu alternatif yang mungkin, $Z_{p}(j=1,2,3, \ldots n)$ yaitu atributs di mana performansi alternatif diukur, $Z_{\mathrm{op}}$ adalah performansi alternatif $Z_{o}$ dengan acuan atribut $Z_{p}$ ternormalisasi, dilihat pada Persamaan (2).

$Q_{o p}=\frac{z_{o p}}{\sqrt{\sum_{o=1}^{m} z_{o p}^{2}}}$

Di mana $\mathrm{Q}_{\mathrm{ij}}$ adalah Matrik ternormalisasi

$[\mathrm{p}] \mathrm{Z}_{\mathrm{op}}$ adalah matriks keputusan [o] [p]. b. Membuat matriks keputusan yang

Jurnal Sistim Informasi dan Teknologi Vol. 3 No. 3 (2021) 142-149 
c. Membuat matriks keputusan ternormalisasi $\mathrm{V}_{\mathrm{op}}$ terbobot. Pada Persamaan (3).

$V_{o p}=W_{o} Q_{o p}$

Dengan o $=1,2, \mathrm{~m} ;$ dan o $=1,2, \mathrm{n}$.

Di mana Vop adalah elemenmatriks keputusan yang ternormalisasi terbobot $\mathrm{V} \mathrm{W}_{\text {op }}$ adalah bobot dari kriteria ke $\mathrm{p}$ dan $\mathrm{Q}_{\mathrm{op}}$ adalah elemen matriks keputusan yang ternormalisasi $\mathrm{M}$.

d. Solusi ideal positif $A+$ dan solusi ideal negatif $A$ - dapat ditentukan berdasarkan rating bobot ternormalisasi $\left(\mathrm{Y}_{\mathrm{op}}\right)$ pada Persamaan (4).

$$
B^{+}=\left(y_{1}^{+}, y_{2}^{+}, \ldots, y_{n}^{+}\right)
$$

$B^{-}=\left(y_{1}^{-}, y_{2}^{-}, \ldots, y_{n}^{-}\right)$.

Di mana $\mathrm{V}_{\mathrm{p}}{ }^{+}$adalah Max $\mathrm{Y}_{\mathrm{op}}$ jika pmerupakan atribut keuntungan (benefit), Min $\mathrm{Y}_{\mathrm{op}}$ jika $\mathrm{p}$ adalah atribut biaya (cost), $\mathrm{V}_{\mathrm{p}}^{-}$adalah $\mathrm{MinY}_{\mathrm{op}}$, jika $\mathrm{p}$ adalah atribut benefit $\mathrm{MaxY}_{\mathrm{op}}$, jika $\mathrm{p}$ adalah atribut cost

e. Jarak antara alternative Ao dengan solusi ideal positif.dilihatpada Persamaan (5).

$E_{o}^{+}=\sqrt{\sum_{o-1}^{n}\left(\mathrm{~V}_{\mathrm{o}}^{+}-\mathrm{V}_{\mathrm{op}}\right)}$

Di mana $\mathrm{E}_{\mathrm{o}}^{+}$adalah Jarak alternativ $B o$ dengan solusi ideal positif, $\mathrm{Y}_{\mathrm{o}}^{+}$adalah Solusi ideal positif [o], $\mathrm{Y}_{\mathrm{op}}$ adalah Matriks normalisasi [o][p]

f. Jarak antara alternatif $B o$ dengan solusi ideal negatif. Dapat dilihat diPersamaan (6)

$E_{i}^{-}=\sqrt{\sum_{i-1}^{n}\left(\mathrm{~V}_{\mathrm{ij}}-\mathrm{V}_{\mathrm{i}}^{-}\right)^{2}}$

i adalah 1,2,m

Di mana $E_{j}$-adalahjarak alternatif $B o$ dengan solusi ideal negatif, $\mathrm{Y}_{\mathrm{p}}$-adalahsolusi ideal positif $\mathrm{Y}_{\mathrm{op}}$ adalahmatriks normalisasi [o][p]

g. Nilai preferensi untuk setiap alternatif $(V o)$. Dapat dilihat pada Persamaan (7).

$V_{o}=\frac{E_{o}^{-}}{E_{o}^{-}+E_{o}^{+}}$

oadalah $1,2, \mathrm{~m}$

Di mana $\mathrm{V}_{\mathrm{o}}$ adalahkedekatan tiap alternatif terhadap solusi ideal, $\mathrm{E}_{\mathrm{o}}^{+}$adalahjarak alternatif $B o$ dengan solusi ideal positif, $\mathrm{E}_{\mathrm{p}}{ }^{-}$adalahjarak alternatif $B o$ dengan solusi ideal negatif. Nilai Vo yang lebih besar menunjukkan bahwa alternatif $B o$ lebih dipilih.

Kerangka kerja penelitian ini merupakan gambaran penelitian secara terstruktur dari penelitian yang akan dilakukan. Berikut ini adalah desain metode penelitian yang digunakan pada proses pembagian beasiswa dengan metode TOPSIS untuk memberikan solusi terbaik dalam pengambilan keputusan menentukan beasiswa.

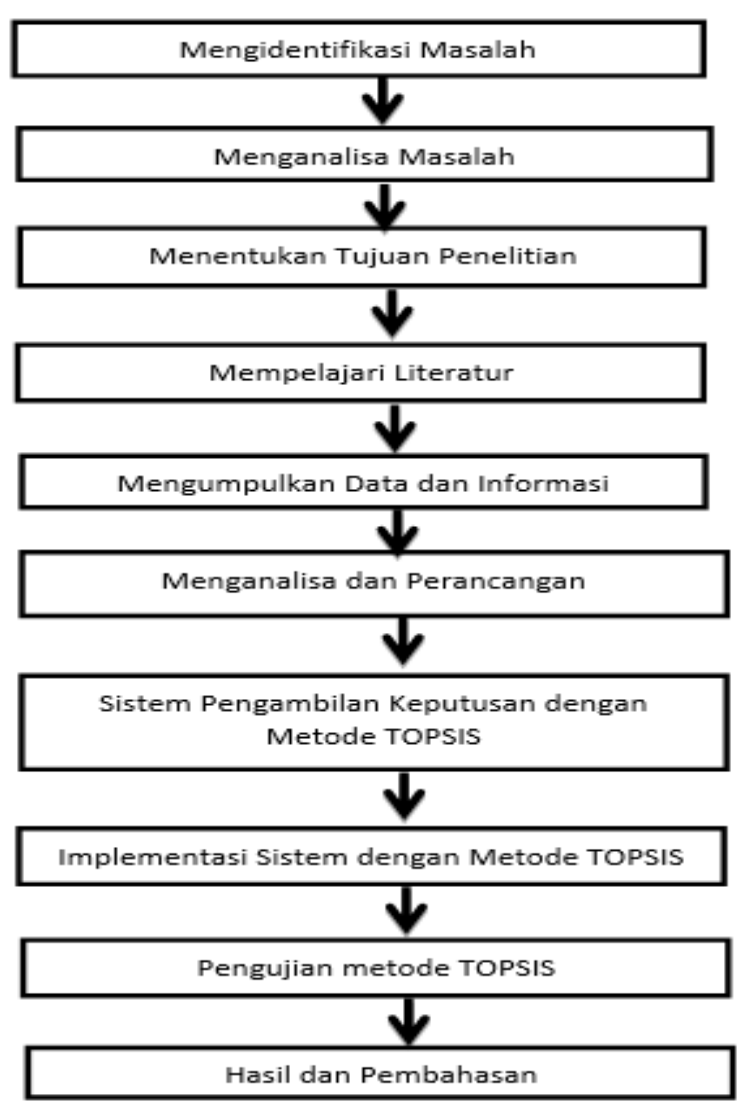

Gambar 1. Kerangka kerja

Adapun uraian tahapan yang dilakukan pada penelitian ini yaitu:

\subsection{Mengidentifikasi Masalah}

Tahapan awal dalam menentukan rumusan masalah yang terjadi pertama yaitu dengan menentukan rumusan masalah yang ditemui pada SMP Negeri 17 Padang dengan penerapan metode TOPSIS dalam menentukan siswa yang benar- benar berhak dalam menerima beasiswa. Identifikasi masalah yang akan dibahas berkaitan dengan sistem pendukung keputusan metode TOPSIS pemberian beasiswa berdasarkan literatur dan informasi yang diperoleh.

\subsection{Menganalisa Masalah}

Langkah analisa masalah ini adalah untuk dapat memahami masalah yang sudah ditentukan ruang lingkupnya atau batasannya.Dengan mempelajari masalah yang telah ditentukan tersebut, maka masalah dapat dipahami dengan baik. Sehingga dari analisa masalah tersebut ditarik sebuah kesimpulan untuk mendapatkan suatu solusi penyelesaian masalah. Pada analisa masalah ini digambarkan proses untuk memprediksi jumlah penerima beasiswa. Dan juga terdapat analisa kebutuhan sistem untuk menentukan keluaran apa saja yang akan didapatkan oleh sistem yang akan dibangun ini. Dari hasil analisa sistem, maka sistem yang akan dibangun ini hendaknya mampu menghasilkan output yaitu informasi dalam penerimaan beasiswa. 


\subsection{Menentukan Tujuan}

Tujuan penelitian adalah suatu hal yang akan dicapai dalam suatu penelitian yang dilakukan. Tujuan penelitian yang diharapkan tercapai setelah hasil akhir ideal dari penelitian tersebut dilakukan. Sebelum penelitian dilakukan tujuan penelitian harus ditentukan diawal terlebih dahulu. Tujuan penelitian sangat diperlukan agar penelitian yang dilakukan bermanfaat bagi penggunaanya.

\subsection{Mempelajari Literatur}

Betapa pentingnya mempelajari dan memahami beberapa literatur yang akan digunakan. Kemudian literatur-literatur tersebut dipelajari, diseleksi dan dipilih literatur mana yang digunakan. Dalam penelitian literatur bersumber dari buku, jurnal-jurnal ilmiah, sumber referensi lainnya. Tujuan mempelajari literatur adalah untuk memberikan kemudahan dalam menyelesaikan permasalahan penelitian sehingga dapat diselesaikan sesegera mungkin.

\subsection{Mengumpulkan Data dan Informasi}

Proses pengumpulan data dilakukan di SMP Negeri 17 Padang untuk mendapatkan data yang nantinya berguna pada penelitian ini. Pengumpulan data pada penelitian ini yaitu data dengan penelusuran terhadap dokumendokumen yang ada untuk mendapatkan data siswasiswa yang telah menerima beasiswa dimasa lampau dan selanjutnya untuk dapat diproses analisis datanya.

\subsection{Menganalisa Studi Kasus}

Pada tahap inidilakukan analisa pemahaman dan perancangan terhadap masalahan yang ada berdasarkan data-data yang dikumpulkan dengan langkah-langkah yang ada dalam metode TOPSIS.Dalam melakukan perancangan dibutuhkan aplikasi pendukung seperti Astah.

\subsection{Perancangan SPK TOPSIS}

Terlebih dahulu ditentukan pemodelan dan variabel. Setelah menentukan variabel yang ada selanjutnya akan dilakukan pengolahan terhadap data yang diperoleh dari pengamatan. Dalam tahapan ini peneliti mencoba menganalia dan merancang sistem yang digunakan untuk menentukan siswa yang seharusnya menerima beasiswa.

\subsection{Implementasi Metode TOPSIS}

Implementasi metode TOPSIS ini digunakan untuk membandingkan hasil yang didapatkan secara manual dengan sistem dimana sebuah sistem yang berbasis komputerisasi ada dua komponen yaitu spesifikasi hardware dan software yang digunakan.

\subsection{Pengujian Metode TOPSIS}

Pada tahap ini dilakukan pengujian terhadap sistem yang telah dibuat akan diuji kinerja dan keefektifannya untuk mengetahui apakah sistem ini dapat berjalan dengan baik atau terdapat kelemahan sistem sehingga perlu diadakan perbaikan terhadap aplikasi dan diperlukan analisa ulang agar dapat berjalan lebih baik agar dapat digunakan lebih efektif serta bermanfaat bagi penggunanya dimana proses pembuatan sistem yang mengacu terhadap hasil analisa dan perancangan sistem dengan kalkulasi menggunakan metode TOPSIS yang diimplementasikan dalam sistem. Untuk pembuatan sistem sendiri yaitu berbasis Web meemakai bahasa pemrograman PHP dan database MySql.

\section{Hasil dan Pembahasan}

Pada penelitian ini, data yangakan digunakan adalah data calon penerima beasiswa. Data yang dibutuhkan diperoleh dari pengambilan langsung ke lapangan dan wawancara dengan staff yang bersangkutan. Berikut adalah data yang akan diolah. Berikut adalah data kriteria yang digunakan sebagai acuan penilaian dalam metode TOPSIS dapat diperhatikan pada Tabel 1.

Tabel 1. Kriteria Penilaian

\begin{tabular}{clclc}
\hline No. & Keterangan & Kriteria & Atribut & Bobot \\
\hline 1. & $\begin{array}{l}\text { Pekerjaan } \\
\text { Orang Tua }\end{array}$ & C1 & Cost & 5 \\
2. & $\begin{array}{l}\text { Tanggungan } \\
\text { Orang Tua }\end{array}$ & C2 & Benefit & 4 \\
3. & $\begin{array}{l}\text { Penghasilan } \\
\text { Orang Tua }\end{array}$ & C3 & Cost & 4 \\
4. & $\begin{array}{l}\text { Rata- rata Nilai } \\
\text { UN }\end{array}$ & C4 & Benefit & 2 \\
5. & Usia Orang Tua & C5 & Benefit & 3 \\
\hline
\end{tabular}

\subsection{Matriks Keputusan}

Berikut tabel data yang diperoleh yang akan dijadikan kedalam bentuk matriks keputusan yang dapat dilihat pada Tabel 2 .

Tabel 2. Penilaian

\begin{tabular}{lccccc}
\hline \multicolumn{1}{c}{ Alternatif } & C1 & C2 & C3 & C4 & C5 \\
\hline Abdiel Maqshud Ibnu H & 4 & 3 & 5 & 3 & 2 \\
Abel Arya Pratama & 3 & 3 & 4 & 4 & 2 \\
Iresa Aulia Zen & 1 & 5 & 1 & 3 & 4 \\
Ibnu Rafiq & 4 & 2 & 5 & 3 & 2 \\
M.Zikra Pratama Putra & 3 & 2 & 3 & 3 & 2 \\
Ririn Dwi Yulianti & 2 & 2 & 1 & 2 & 1 \\
\hline
\end{tabular}

Data yang ada pada tabel dijadikan kedalam bentuk matriks keputusannya adalah:

$$
Z=\left[\begin{array}{l}
43532 \\
33442 \\
12134 \\
42532 \\
32332 \\
22221
\end{array}\right]
$$

\subsection{Matriks Ternomalisasi}

Normalisasi matriks dengan menyatukan setiap elemen matriks untuk mendapatkan skala nilai yang sama untuk setiap kriteria

$$
\begin{aligned}
& \mathrm{ZI}=\sqrt{4^{2}+3^{2}+1^{2}+4^{2}+3^{2}+2^{2}}=7,42 \\
& Q_{11}=\frac{4}{7,42}=0,5394 \\
& Q_{21}=\frac{3}{7,42}=0,4045
\end{aligned}
$$




$$
\begin{aligned}
& Q_{31}=\frac{1}{7,42}=0,1348 \\
& Q_{41}=\frac{4}{7,42}=0,5394 \\
& Q_{51}=\frac{3}{7,42}=0,4045 \\
& Q_{61}=\frac{2}{7,42}=0,2697 \\
& \mathrm{Z} 2=\sqrt{3^{2}+3^{2}+2^{2}+2^{2}+2^{2}+2^{2}}=5,83 \\
& Q_{12}=\frac{3}{5,83}=0,5145 \\
& Q_{22}=\frac{3}{5,83}=0,5145 \\
& Q_{32}=\frac{2}{5,83}=0,3430 \\
& Q_{42}=\frac{2}{5,83}=0,3430 \\
& Q_{52}=\frac{2}{5,83}=0,3430 \\
& Q_{62}=\frac{2}{5,83}=0,3430 \\
& \mathrm{Z3}=\sqrt{5^{2}+4^{2}+1^{2}+5^{2}+3^{2}+2^{2}}=8,94 \\
& Q_{13}=\frac{5}{8,94}=0,5590 \\
& Q_{23}=\frac{4}{8,94}=0,4472 \\
& Q_{33}=\frac{1}{8,94}=0,1118 \\
& Q_{43}=\frac{5}{8,94}=0,5590 \\
& Q_{53}=\frac{3}{8,94}=0,3354 \\
& Q_{63}=\frac{2}{8,94}=0,2236 \\
& \mathrm{Z} 4=\sqrt{3^{2}+4^{2}+3^{2}+3^{2}+3^{2}+2^{2}}=7,48 \\
& Q_{14}=\frac{3}{7,48}=0,4009 \\
& Q_{24}=\frac{4}{7,48}=0,5345 \\
& Q_{34}=\frac{3}{7,48}=0,4009 \\
& Q_{44}=\frac{3}{7,48}=0,4009 \\
& Q_{54}=\frac{3}{7,48}=0,4009 \\
& Q_{64}=\frac{2}{7,48}=0,2673 \\
& \begin{array}{l}
\mathrm{Z} 5=\sqrt{2^{2}+2^{2}+4^{2}+2^{2}+2^{2}+1^{2}}=5,74 \\
Q_{15}=\frac{2}{5,74}=0,3482 \\
Q_{25}=\frac{2}{5,74}=0,3482 \\
Q_{35}=\frac{4}{5,74}=0,6963 \\
Q_{45}=\frac{2}{5,74}=0,3482 \\
Q_{55}=\frac{2}{5,74}=0,3482 \\
Q_{65}=\frac{1}{5,74}=0,1741
\end{array} \\
& M=\left[\begin{array}{l}
0,53940,51450,55900,40090,3482 \\
0,40450,51450,44720,53450,3482 \\
0,13480,34300,11180,40090,6963 \\
0,53940,34300,55900,40090,3482 \\
0,40450,34300,33540,40090,3482 \\
0,26970,34300,22360,26730,1741
\end{array}\right] \\
& \text { 3.3.Matriks Ternormalisasi Terbobot } \\
& y_{11}=w_{1} \times Q_{11}=5 \times 0,5394=2,6968 \\
& y_{21}=w_{1} \times Q_{21}=5 \times 0,4045=2,0226 \\
& y_{31}=w_{1} \times Q_{31}=5 \times 0,1348=0,6742 \\
& y_{41}=w_{1} \times Q_{41}=5 \times 0,5394=2,6968 \\
& y_{51}=w_{1} \times Q_{51}=5 \times 0,4045=2,0226 \\
& y_{61}=w_{1} \times Q_{61}=5 \times 0,2697=1,3484 \\
& y_{12}=w_{2} \times Q_{12}=4 \times 0,5145=2,0580 \\
& y_{22}=w_{2} \times Q_{22}=4 \times 0,5145=2,0580 \\
& y_{32}=w_{2} \times Q_{32}=4 \times 0,3430=1,3720 \\
& y_{42}=w_{2} \times Q_{42}=4 \times 0,3430=0,3720 \\
& y_{52}=w_{2} \times Q_{52}=4 \times 0,3430=0,3720 \\
& y_{62}=w_{2} \times Q_{62}=4 \times 0,3430=0,3720 \\
& y_{13}=w_{3} \times Q_{13}=4 \times 0,5590=2,2361 \\
& y_{23}=w_{3} \times Q_{23}=4 \times 0,4472=1,7889 \\
& y_{33}=w_{3} \times Q_{33}=4 \times 0,1118=0,4472 \\
& y_{43}=w_{3} \times Q_{43}=4 \times 0,5590=2,2361
\end{aligned}
$$

Jurnal Sistim Informasi dan Teknologi Vol. 3 No. 3 (2021) 142-149 
Dina Ayudia, Gunadi Widi Nurcahyo, Sumijan.

$y_{53}=w_{3} \times Q_{53}=4 \times 0,3354=1,3416$
$y_{63}=w_{3} \times Q_{63}=4 \times 0,2236=0,8944$
$y_{14}=w_{4} \times Q_{14}=2 \times 0,4009=0,8018$
$y_{24}=w_{4} \times Q_{24}=2 \times 0,5345=1,0690$
$y_{34}=w_{4} \times Q_{34}=2 \times 0,4009=0,8018$
$y_{44}=w_{4} \times Q_{44}=2 \times 0,4009=0,8018$
$y_{54}=w_{4} \times Q_{54}=2 \times 0,4009=0,8018$
$y_{64}=w_{4} \times Q_{64}=2 \times 0,2673=0,5345$
$y_{15}=w_{5} \times Q_{15}=3 \times 0,3482=1,0445$
$y_{25}=w_{5} \times Q_{25}=3 \times 0,3482=1,0445$
$y_{35}=w_{5} \times Q_{35}=3 \times 0,6963=2,0889$
$y_{45}=w_{5} \times Q_{45}=3 \times 0,3482=1,0445$
$y_{55}=w_{5} \times Q_{55}=3 \times 0,3482=1,0445$
$y_{65}=w_{5} \times Q_{65}=3 \times 0,1741=0,5222$

Dari perhitungan sebelumnya diperoleh matriks ternormalisasi terbobot

$$
Y=\left[\begin{array}{llll}
2,6968 & 2,0580 & 2,23610,8018 & 1,0445 \\
2,0226 & 2,0580 & 1,78891,0690 & 1,0445 \\
0,67421,3720 & 0,44720,80182,0889 \\
2,6968 & 1,3720 & 2,23610,80181,0445 \\
2,0226 & 1,3720 & 1,34160,80181,0445 \\
1,3484 & 1,3720 & 0,89440,5345 & 0,5222
\end{array}\right]
$$

3.4 Solisi Ideal Positif dan Negatif

Penentuan matriks solusi ideal positif dan negatif diperoleh dari matriks bobot ternormalisasi. Syaratnya yaitu bisa menghitung nilai solusi ideal dengan terlebih dahulu menentukan apakah bersifat benefit atau cost.

1. Menentukan matriks ideal positif (positif: (max|benefit) $(\min \mid$ cost $)$

$\mathrm{Y}_{1}^{+}=\max \{2,6968 ; 2,0226 ; 0,6742 ; 2,6968 ; 2,0226 ; 1,3484\}$

$=0,6742$

$\mathrm{Y}_{2}^{+}=\max \{2,0580 ; 2,0580 ; 1,3720 ; 1,3720 ; 1,3720 ; 1,3720\}$

$=2,0580$

$\mathrm{Y}_{3}^{+}=\max \{2,2361 ; 1,7889 ; 0,4472 ; 2,2361 ; 1,3416 ; 0,8944\}$

$=0,4472$

$\mathrm{Y}_{4}^{+}=\max \{0,8018 ; 1,0690 ; 0,8018 ; 0,8018 ; 0,8018 ; 0,5345\}$

$=1,0690$

$\mathrm{Y}_{5}^{+}=\max \{1,0445 ; 1,0445 ; 2,0889 ; 1,0445 ; 1,0445 ; 0,5222\}$

$=2,0889$

$$
\begin{aligned}
& \longdiv { ( 2 , 0 2 2 6 - 3 , 1 6 1 ) ^ { 2 } + ( 1 , 3 7 2 0 - 0 , 8 9 4 ) ^ { 2 } } \\
& E_{5}^{-}=\quad+(1,3416-2,6492)^{2} \\
& +(0,8018-0,5186)^{2} \\
& +(1,0445-0,8943)^{2} \\
& =2,0618
\end{aligned}
$$

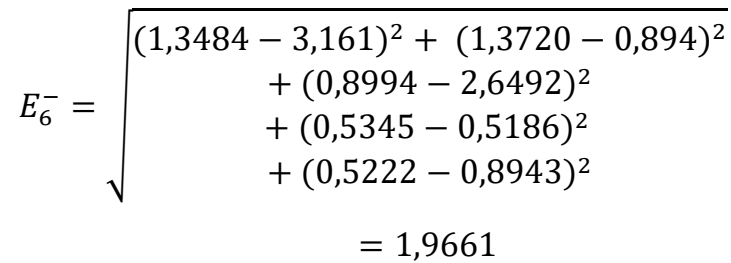

2. Menentukan matriks ideal negatif (min|benefit)( 2.Menentukan jarak nilai terbobot setiap alternatif $\max \mid \cos t)$

$Y 1-=\min \{2,6968 ; 2,0226 ; 0,6742 ; 2,6968 ; 2,0226 ; 1,3484\}$

$=2,6968$ terhadap solusi ideal negatif 


\begin{tabular}{|c|c|c|c|c|c|}
\hline \multirow{8}{*}{$E_{1}^{-}=$} & \multirow{6}{*}{ 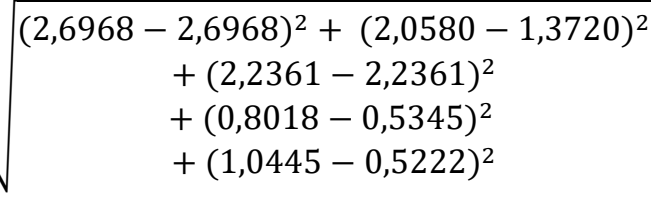 } & \multicolumn{4}{|c|}{ Tabel 3. Nilai Preferensi untuk Alternatif } \\
\hline & & No & Nama Siswa & Hasil & Rank \\
\hline & & 1 & Iresa Aulia Zein & 7,39 & 1 \\
\hline & & 2 & Ririn & 2,87 & 2 \\
\hline & & 3 & Abel Arya Pratama & 1,90 & 3 \\
\hline & & 4 & Zikra & 1,88 & 4 \\
\hline & $=0,9026$ & 5 & Abdil & 1,21 & 5 \\
\hline & & 6 & Ibnu & 0,78 & 6 \\
\hline
\end{tabular}

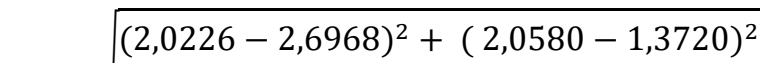

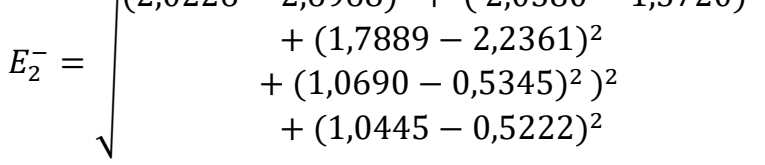

$$
\begin{aligned}
& =1,2975
\end{aligned}
$$

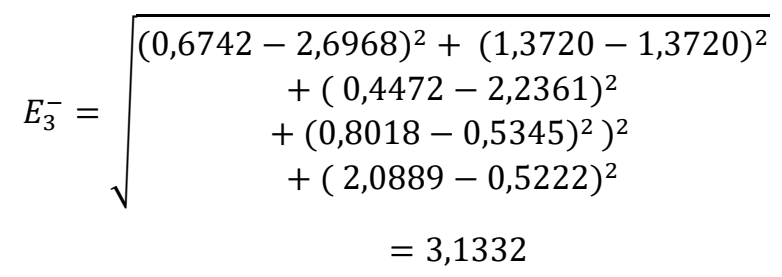

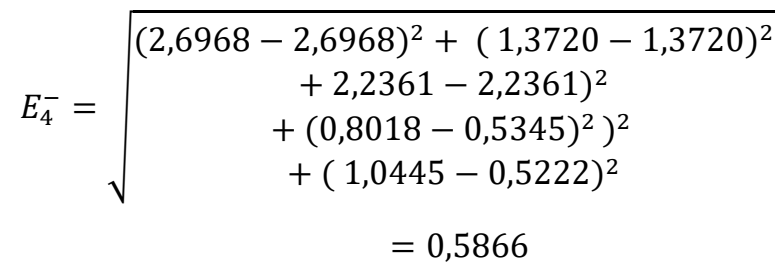

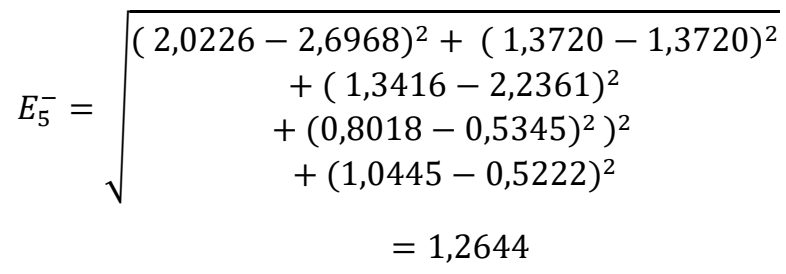

3.6 Nilai Preferensi setiap alternatif

Dari hasil penentuan jarak solusi ideal dan preferensi, dapat ditentukan nilai preferensi setiap alternatif sebagai berikut

$$
\begin{aligned}
& \mathrm{V} 1=\frac{0,9026}{2,9074+0,9026}=1,2131 \\
& \mathrm{~V} 2=\frac{1,2975}{2,1700+1,2975}=1,8955 \\
& \mathrm{~V} 3=\frac{3,1332}{0,7362+3,1332}=7,3890 \\
& \mathrm{~V} 4=\frac{0,5866}{2,9873+0,5866}=0,7830 \\
& \mathrm{~V} 5=\frac{1,2644}{2,0618+1,2644}=0,18776 \\
& \mathrm{~V} 6=\frac{1,9022}{1,9661+1,9022}=0,28696
\end{aligned}
$$

Hasil yang didapat dari penentuan nilai preferensi alternatif dapat dijelaskan di Tabel 3.
Berdasarkan hasil kalkulasi nilai preferensi untuk tiaptiap alternatif maka nilai tertinggi terdapat pada alternatif dengan kode S03 (Iresa Aulia Zein) dengan nilai 07.39 merupakan alternatif yang terpilih sebagai siswa yang menjadi penerima beasiswa.

\section{Kesimpulan}

Metode TOPSIS bisa digunakan untuk menentukan pemberian beasiswa.Metode TOPSIS dalam penilaian pemberian beasiswa dapat membantu keputusan pada siswa kelas 7 SMP Negeri 17 Padang secara proporsional. Artibut proses kalkualsi data siswa terdiri ataskartu keluarga, pekerjaan orang tua, pendapatan orang tua, banyak tanggungan orang tua dan umur orang tua. Hasil pengolahan mendapatkan keputusan yang tepat, cepat, dan akurat karena sistem pendukung keputusan meminimalkan kesalahan dalam proses kalkulasi normalisasi data. Siswa yang mendapatkan beasiswa diberikan kepada Iresa Aulia Zein dengan nilai 7.39 .

\section{Daftar Rujukan}

[1] Renaldo, R., Anggraeni, E. Y., \& HC, E. R. (2019). Metode Topsis dalam Sistem Pendukung Keputusan Penentuan Penerimaan Beasiswa di STMIK Pringsewu. EXPERT: Jurnal Manajemen Sistem Informasi dan Teknologi, 9(1). DOI: http://dx.doi.org/10.36448/jmsit.v9i1.1225 .

[2] Sunalia, A., Abdillah, L. A., \& Jarwosuwito, S. (2017). Sistem Pendukung Keputusan Penentuan Penerima Beasiswa pada SMK Madyatama dengan Metode TOPSIS. In Seminar Nasional Penelitian Ilmu Komputer Ke-2 (SENTIKOM).

[3] Wang, V. V., Sukamto, A. S., \& Pratama, E. E. (2019). Sistem Pendukung Keputusan Seleksi Mahasiswa Penerima Beasiswa BBP-PPA dengan Metode TOPSIS pada Fakultas Teknik UNTAN. Jurnal Sistem dan Teknologi Informasi (JUSTIN), 7(2). DOI: http://dx.doi.org/10.26418/justin.v7i2.29656 .

[4] Sari, R. (2018). Sistem Pendukung Keputusan Pemilihan Siswa Penerima Beasiswa dengan Metode Topsis. Evolusi: Jurnal Sains dan Manajemen, 6(2). DOI: https://doi.org/10.31294/evolusi.v6i2.4426 .

[5] Liesnaningsih, L., Taufiq, R., Destriana, R., \& Suyitno, A. P. (2020). Sistem Pendukung Keputusan Penerima Beasiswa Berbasis WEB Menggunakan Metode Simple Additive Weighting (SAW) pada Pondok Pesantren Daarul Ahsan. Jurnal Informatika Universitas Pamulang, 5(1). DOI: http://dx.doi.org/10.32493/informatika.v5i1.4664 .

[6] Dawis, A. M. (2020). Sistem Pendukung Keputusan Pemberian Reward Pegawai Menggunakan Metode TOPSIS. Jurnal Ilmiah SINUS, 18(1). DOI: https://doi.org/10.30646/sinus.v18i1.429

[7] Sunalia, A., Abdillah, L. A., \& Suyanto. (2017). Sistem Pendukung Keputusan Penentuan Penerima Beasiswa pada SMK Madyatama dengan Metode TOPSIS. Sentikom. DOI: https://doi.org/10.31227/osf.io/d3kus .

[8] Heriawan, I. G. T., \& Subawa, I. G. B. (2019). Sistem Pendukung Keputusan Pemberian Beasiswa Bidikmisi Menggunakan Metode SAW-TOPSIS di Stahn Mpu Kuturan Singaraja. JST (Jurnal Sains dan Teknologi), 8(2). DOI: http://doi:10.23887/jst-undiksha.v8i2.21197 . 
Dina Ayudia, Gunadi Widi Nurcahyo, Sumijan.

[9] Sukiman., Hendry., Jimmy., Sugianto., Waisen., \& Suryati, L. [10]Ramadiani, Hatta, H. R., Novita, N., \& Azainil. (2019). (2020). Decision Support System for Academic Administration Staff Achievement in STMIK IBBI Using TOPSIS-HFLTS Method. 3rd International Conference on Mechanical, Electronics, Computer, and Industrial Technology (MECnIT). Comparison of Two Methods Between TOPSIS and MAUT In Determining BIDIKMISI Scholarship. Third International Conference on Informatics and Computing (ICIC). DOI: https://doi.org/10.1109/MECnIT48290.2020.9166660 . 